\title{
RESEARCH ETHICS TRAINING OF TRAINERS: DEVELOPING CAPACITY OF BOLIVIAN HEALTH SCIENCE AND CIVIL SOCIETY LEADERS
}

\begin{abstract}
Annette Aalborg ${ }^{1}$, Sarah Sullivan ${ }^{1}$, Jacqueline Cortes ${ }^{2}$, Armando Basagoitia ${ }^{3}$, Daniel Illanes ${ }^{4}$, Matthew Green $^{1}$

Abstract: Research and research ethics (RE) capacity is a key element for addressing health priorities of low - and middleincome countries (LMICs). With support from a NIH/FIC Research Ethics Education and Curriculum Development grant, a RE Training of Trainers (TOT) was implemented in Bolivia. The Steering Committee, including representatives from four Bolivian universities and PAHO, developed the RE TOT that included face-to-face, online and practicum components. Twenty trainees including faculty, researchers and community leaders participated. Pre/Posttest results demonstrated significant increases in overall RE knowledge $(13.1 \%$ improvement, p-value $<0.0001)$. An evaluation demonstrated participants valued participatory learning strategies and the flexibility of the online component. TOT participants during the practicum component delivered RE workshops to their university and civil society communities in four regions ( $n=3,700$ people). The goals of the grant were accomplished through the development of a Steering Committee and implementation of the TOT course. Next steps include the design and implementation of a master's level research ethics education program in Bolivia.
\end{abstract}

Key words: research ethics education, training of trainers (TOT), research ethics programs, low - and middle - income countries (LMICS)

Formación en ética de investigación para profesionales: desarrollando capacidades para las ciencias de la salud y líderes de la sociedad civil en Bolivia

Resumen: La capacidad de investigación y ética de la investigación (EI) es un elemento clave para hacer frente a las prioridades de salud de los países de ingresos bajos y medios (PIBM). Con el apoyo de la subvención de ética de la Investigación de NIH/ FIC, una capacitación para capacitadores (CPC) fue implementado en Bolivia. El Comité Directivo, que incluye representantes de universidades y la OPS, desarrolló un CPC en EI que incluía componentes presenciales, virtuales y de práctica. Veinte participantes, incluyendo docentes, investigadores y líderes de la comunidad participaron. Los resultados de la pre/post prueba demostraron aumentos significativos en el conocimiento de EI $(13,1 \%$ de mejora, valor de $\mathrm{p}<0,0001)$. Una evaluación demostró que los participantes valoraron las estrategias de aprendizaje y la flexibilidad del componente virtual. Durante el componente de prácticas, los participantes hicieron talleres de EI que fueron presentados a sus comunidades universitarias y a la sociedad civil en cuatro regiones ( $\mathrm{n}=3,700$ personas). Los objetivos de la subvención se llevaron a cabo mediante el desarrollo de un Comité Directivo y la implementación del CPC. Los próximos pasos incluyen el diseńo e implementación de un programa de educación en ética de investigación a nivel de maestría en Bolivia.

Palabras clave: educación en ética de la investigación, capacitación de capacitadores (CPC), programas de ética de la investigación, países de ingresos bajos y medios (PIBM)

Pesquisa ética no treinamento de estagiários: desenvolvendo a capacitação da ciência da saúde boliviana e em líderes da sociedade civil

Resumo: Capacitação em pesquisa e ética em pesquisa (RE) de capacidade é um elemento-chave para abordar as prioridades de saúde em países de baixa e média renda (LMICs). Com o apoio de bolsa do NIH / FIC Research Ethics Education and Curriculum Development, uma RE Training of Trainers (TOT) foi implantada na Bolívia. O Comitê Dirigente, incluindo representantes das universidades bolivianas e PAHO, desenvolveu a RE TOT que envolveu modo presencial, online e componentes práticos. Participaram vinte estagiários, incluindo faculdades, pesquisadores e líderes comunitarios. Resultados pré / pós-teste demonstraram aumentos significativos no conhecimento RE geral (melhoria de 13,1\%, p <0,0001). Uma avaliaçáo demonstrou participantes valorizados por estratégias de aprendizagem participativa e a flexibilidade do componente online de participantes. Participantes TOT realizaram workshps da prática RE fornecida às suas comunidades universitárias e à sociedade civil em quatro regiôes $(\mathrm{n}=3.700$ pessoas). Os objetivos da subvenção foram realizadas através do desenvolvimento de uma Comissão de Coordenação e implementação do curso TOT. Os próximos passos incluem a concepção e implementação de programa de educação em ética da investigação, ao nível de mestrado, na Bolívia.

Palavras-chave: educação em pesquisa ética, treinamento de estagiários (TOT), programas de pesquisa ética em países de baixa e média renda (LMICS)

\footnotetext{
${ }^{1}$ Touro University California, Vallejo, USA

Correspondence: annette.aalborg@tu.edu

${ }^{2}$ Universidad Mayor de San Andrés, La Paz, Bolivia

${ }^{3}$ Universidad Mayor, Real y Pontificia de San Francisco Xavier, Chuquisaca, Bolivia

${ }^{4}$ Universidad Mayor de San Simon, Cochabamba, Bolivia
} 


\section{Introduction}

Supporting local researchers and institutions in developing countries to conduct high quality health research is a critical step towards improving the health of the population. Increasing the capacity of academics, researchers and health professionals to strengthen research infrastructure will facilitate meeting the Sustainable Development Goals (SDGs)(1). The health-related SDGs address issues of poverty, agriculture, education, gender, water and sanitation, energy, consumption, economic growth, inequality, housing, climate change, and sustainable development. These issues are central to the Bolivian constitution and the National Development Plan (NDP) that aim to improve the lives of all Bolivians with a particular focus on marginalized indigenous peoples(2).

In Bolivia, recent political, social, and economic advances have increased interest in strengthening the national research agenda and in developing sustainable approaches to supporting research(3) however; research capacity has been historically limited by insufficient funding and support. In 2013, the Swedish International Development Agency (SIDA, provided approximately 25 million USD (216 MSEK) for the 2013-2017 period to strengthen research capacity in Bolivia through education, funding of research projects, and support to university administration (4). The national conversation among scientists suggests that the time is right to develop educational programs to improve the ability of Bolivian researchers to conduct research that incorporates ethical practices with the goal of improving health for all(3).

Few academics, researchers and health professionals have received formal training in research ethics (RE) and there are significant challenges to the consistent application of RE practices in the conduct of research $(5,6)$. A study assessing the status of RE practice in Bolivia reported a lack of knowledge on how to protect research subjects and an absence of functioning research ethics committees (RECs), insufficient RE infrastructural support and RE training(3). These findings highlight the importance of developing a systematic approach to RE education and support for strengthening institutional policies and practices.
To address these needs, the Universidad Mayor de San Andrés (UMSA) in La Paz, Bolivia, in collaboration with Touro University California (TUC), applied for an International Research Ethics Education and Curriculum Development Award (R25) funded by the United States' National Institutes of Health/Fogarty International Center (NIH/FIC) in June 2012(7). UMSA was awarded the 2-year Comprehensive Bolivia Specific Multi-level Research Ethics Education Planning Grant (5R25TW009509) to develop initial strategies for future implementation of a national RE program in Bolivia.

A principle aim of the grant was to develop, implement and evaluate a Research Ethics Training of Trainers (TOT) course with the goal of training faculty and mentors for implementation of a national RE program. Improvement in RE knowledge and skills is an important education outcome; however, RE training is also critical to broaden research ethics related attitudes and perceptions $(8,9)$.

\section{Study Aims}

The principle aim of this paper is to evaluate the Bolivian TOT Research Ethics Course implemented during July-September, 2014 as a part of Bolivian RE Education Planning Grant. We will focus on a description of the collaborative process of course development and implementation including curriculum design, participant recruitment and course implementation strategies. We also assess participant evaluation of the course utilizing self-administered participant satisfaction questionnaires administered after the face-to-face and online course components and change in RE ethics knowledge and skills through administration of Pre/Posttest. We also describe participants' efforts to disseminate RE educational activities in each of their home universities and regional communities. Finally we summarize lessons learned and implications for future RE educational programs in Bolivia.

\section{Methodology}

\section{Steering Committee}

To guide development of the project and develop 
RE leadership, a Steering Committee with representation from the public universities partners and other key planning grant partners wascreated. The Steering Committee included two representatives from each of the four universities (UMSA in La Paz, the Universidad Mayor Real y Pontificia de San Francisco Xavier (UMRPSFX) in Chuquisaca, the Universidad Mayor de San Simon (UMSS) in Cochabamba, and the Universidad Autónoma Gabriel René Moreno (UAGRM) in Santa Cruz), a representative from the World Health Organization (WHO) in Bolivia and two representatives from the TUC Public Health program. University representatives were all faculty with significant experience in research and/ or research ethics. The WHO representative had significant experience in research and online pedagogy. Several of the Bolivian Steering Committee members had participated in international, national and regional Bioethics and RE symposiums. One of the members had recently completed a master's level RE course in Argentina funded by the NIH/FIC. The Steering Committee met quarterly throughout the Planning Grant period to develop and coordinate all aspects of the TOT course, rotating meeting sites between each of the four principle regional partners. These meetings facilitated sharing of perspectives, knowledge and resources among all members.

\section{Curriculum Development}

Steering Committee members developed a draft Research Ethics TOT course. National and international documents were utilized to provide guidance for course planning. The course modules included materials developed by Bolivian academics and international researchers from bioethics and RE programs at UNESCO, WHO and CITI (Collaborative Institutional Training Initiative). Bolivian national health policies and research priorities were selected as priority topics to include in the curriculum. Health and human rights were selected as cross cutting themes with a focus on research with vulnerable groups such as marginalized indigenous populations and patients. See Table 1 below for module descriptions.

\section{Adult Learning Methods}

The development of the research ethics cur- riculum was informed by adult learning educational principles including using interactive learning methods, emphasizing skills relevant to "real world" environments, and including participants actively in the learning and assessment process (10). Teaching methods, such as lectures, modular instruction, role-plays, and small group discussions were used to adapt to the different learning styles of the participants(11-14). By applying adult learning theories, the course leaders prioritized helping learners lay the foundations for a career of life-long development in the RE field(15). The curriculum emphasized an integration of the unique backgrounds of the different types of participants which may enhance the richness of activities such as the role-playing practices and other group activities(10). The TOT program incorporated a blended educational design that included dynamic didactic components along with a flexible online component which has been suggested to be an effective learning approach for adult professionals(16). Researchers in Bolivia have reported in a recent needs assessment that of all course styles, they would rank a hybrid course that included face-to- face and distance learning components as most preferred(3).

\section{Hybrid Course Design}

The TOT research ethics course was a hybrid of bioethics and RE educational activities and materials delivered face-to-face utilizing interactive learning strategies and online utilizing distance learning methodologies, followed by a supervised practicum. The three day face-to-face component was followed by the 10 week self-paced online component. After completion of the didactic learning components, the practicum was conducted over 3 months. Each of the eight RE modules had a face-to-face component and an online component. An additional eight CITI modules were included in the online component.

The face-to-face component utilized interactive learning strategies with significant focus on discussion of theoretical content and group activities. Each module was prepared by the faculty selected to teach that module and included dynamic group work, case studies, and round table discussions. The online modules were selfpaced with homework and assigned activities 
with ongoing feedback from the instructors. An Academic Course Coordinator with expertise in online instruction provided technical support and supervision.

\section{Education Practicum}

Upon completion of the training, participants were encouraged to implement educational RE activities in their local communities and institutions. Participants strengthened their knowledge of research ethics and gained important teaching skills among diverse groups of health science students, faculty, community members, healthcare professionals, leaders of civil organizations, and Research Ethic Committee members.

\section{TOT Faculty}

National and international health science leaders from the Ministry of Health, WHO, universities and community organizations were selected to teach the modules. The majority of faculty represented Bolivian universities and health organizations. The faculty that taught the face-to-face modules also taught the online modules with the exception of Dr. Fernando Lolas, an international RE expert, who taught the Global Research Enterprise and Publications module.

\section{Participant Recruitment}

The Steering Committee developed the TOT participant recruitment plan. Four university faculty and one civil society representative were purposively selected from each of the four participating regional universities/states for a total of 20 invited participants. Steering Committee members selected four faculty members from different departments in their Medical/Health Science universities who had RE experience. One civil society/community health leader from each region/ state was invited to attend the training representing groups such as Human Rights organizations, the Catholic Church or HIV/AIDS advocate organizations.

\section{Course Participation}

All those who were selected agreed to attend with 19 participants attending the three day face-to face-TOT training. Eight Steering Committee members and nine additional TOT faculty participated in the face-to-face component of the TOT. Several of these Steering Committee members and faculty chose to participate and completed the online modules. Members of the Steering Committee and faculty who participated in

Table 1. Modules

\begin{tabular}{|l|l|}
\hline $\begin{array}{l}\text { Research Ethics Curriculum Modules } \\
\text { (Face-to-face and online) }\end{array}$ & Content Topic \\
\hline Module 1 & Bioethics and Research Ethics History and Principles \\
\hline Module 2 & Bolivian policies related to health and health research \\
\hline Module 3 & Health and Human Rights \\
\hline Module 4 & Standards of Good Clinical Practice and Clinical Trials \\
\hline Module 5 & Informed Consent - \\
\hline Module 6 & Vulnerable Populations - Ethics and risk assessment ( \\
\hline Module 7 & RE Committees - Structure, Functions, monitoring and regulations \\
\hline Module 8 & Responsible Conduct of Research \\
\hline Online Modules & 1) Student Researchers and Student Participants in Research \\
& 2) CIOMS Guidelines 2002 \\
& 3) Privacy and Confidentiality \\
& 4) Genetic Research \\
& 5) Research using Data from Patient Charts \\
& 6) International Research \\
& 7) Research using the Internet \\
\hline
\end{tabular}


the course components were not included in the data analysis evaluating the course components reported below.

\section{Research Ethics Committee Approval}

The study was reviewed and approved by the TUC IRB and the Comité de Bioética Facultad de Medicina, Universidad Mayor de San Simón, Bolivia. The aims of the study, study procedures and the informed consent (IC) process were explained prior to beginning the TOT training. All participants gave their written informed consent.

\section{Study Instruments and Procedures}

TOT Pre/Posttests which measured RE knowledge and skills were used to assess changes in RE ethics knowledge from baseline to course completion. Data from the participant Satisfaction and attitudes Questionnaires administered after each educational component were used to assess the quality and usefulness of the teaching methods and materials.

\section{- TOT Pre/Posttests}

The Pre/Posttest included 20 multiple choice and true/false questions for a total of 44 potential correct answers/points. The Pre/Posttest was adapted from the Family Heath International (FHI) research ethics training curriculum test (17). Participants took the Pre/posttest before the faceto-face component and after completing the online components. The questionnaire measured the participants' knowledge in 5 areas : Research Ethics Principles, Research Ethics Fundamentals, Responsible Conduct of Research, Research Supervision, and Special RE Themes.

\section{- Completion of Online Modules}

Data regarding completion of the Online Modules was used to measure participant success in the online course component. Participation in virtual chats, online case studies and homework assignments were used to assess completion of the modules.

\section{- Satisfaction and Attitudes Questionnaires}

The anonymous, self- administered Participant
Satisfaction and Attitudes Questionnaires were administered after the face-to-face course and online components. This data was used to assess the quality and usefulness of the teaching methods and materials. The questionnaires were identical for each component except for one section of five questions that related to the specific course delivery methods. The satisfaction and attitudes questionnaires were also adapted from the FHI course (17). The satisfaction and attitudes questionnaires included 24 questions assessing participants' opinions on the relevance of course topics, previous RE training, attitudes related to $\mathrm{RE}$ principles and practices, and satisfaction with course delivery methods. Participants also responded to open-ended questions focused on participants' perceptions and attitudes related to the course.

Results

\section{TOT Pre/Posttests}

Nineteen participants completed pretests and thirteen participants completed posttests after they finished both the face to face and online components. The six participants who did not complete the Posttest were not different from the other participants in any demographic characteristic measured.

Figure 1 demonstrates the difference (13.1\%) between the mean Pretest score (67.36\%) and the mean Posttest score (80.46\%) for the 13 participants that completed both the pre and posttest. A paired t-test yields a significant p-value < 0.0001 .

Figure 1. Mean Test Scores, n=13

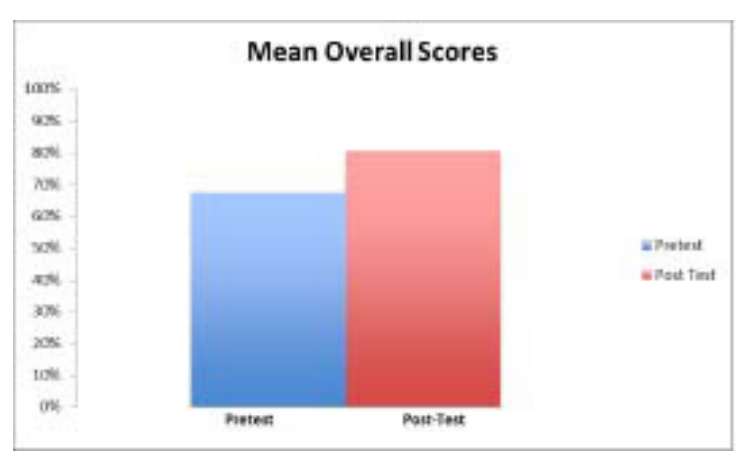


Figure 2. Participant Score Comparison, $n=13$

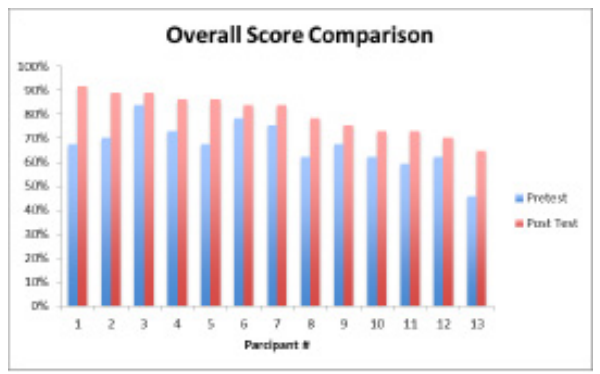

Figure 2 shows the change in score between pre and posttests. The highest individual posttest score was $92 \%$ and the lowest was $65 \%$. All participants demonstrated improvement in their scores. Participant $(\mathrm{n}=9)$ scores of University faculty improved by $14.11 \%$ from a $69.37 \%$ to $83.48 \%$, while community participants $(n=4)$ scores improved $10.81 \%$ from a $62.84 \%$ to $73.65 \%$.

Figure 3 depicts the average scores by content theme. Participants increased knowledge in all areas including Research Ethics Principles, Responsible Conduct of Research, Research Ethics Fundamentals, Special Themes, and Research Supervision.

Figure 3. Knowledge scores by Content Section, $\mathrm{n}=13$

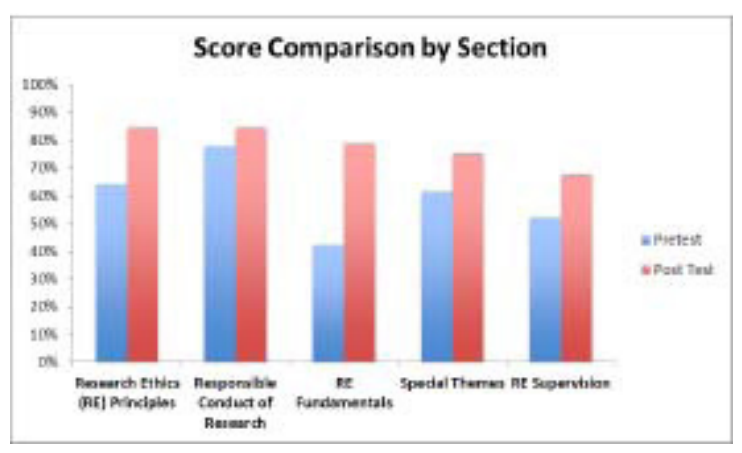

The area where most improvement was seen was Research Ethics Fundamentals that included topics such as the Nuremberg Code, Declaration of Helsinki and the Belmont Report.

\section{Completion of Online Modules}

Of the 19 participants, 16 (84\%) completed at least seven modules. There was no difference in module completion between the university faculty and community member participants.

\section{Satisfaction and Attitudes Questionnaires}

Twenty six people evaluated the face-to-face training component (including 19 TOT participants and 7 Steering Committee members and course faculty) and 14 completed the online component questionnaire. The majority of respondents (52\%) had attended short trainings (less than one week) in bioethics and/or research ethics. Five (19\%) of the respondents had not received any bioethics or $\mathrm{RE}$ training and six respondents $(23 \%)$ had attended a longer than one week training. Among those completing the online training, most respondents $(64 \%)$ reported that the instructions for using the virtual platform were clear and they received sufficient support from the Course Coordinator $(86 \%)$, however, many stated $(57 \%)$ that only some of the teachers provided sufficient academic support for the online course component.

As part of the qualitative data analysis process concerning positive and negative course aspects, open-ended survey responses were compiled, reviewed, and coded using "grounded theory" inductive procedures for analyzing qualitative data as described by Glaser and Strauss(18). Similar words/phrases were grouped together and a constant comparison approach was applied by two researchers. The open-ended questions allowed for more than one response and all responses were categorized. In response to the question asking for positive aspects of the in person training, there were 81 separate responses which were categorized into four themes: Participant characteristics, Pedagogy, New knowledge/information, and Curriculum/teachers. Other open-ended questions relating to positive and negative aspects of the face to face and online component were compiled, coded and analyzed using this same process. The themes and numbers of responses for each theme are presented in Table 2.

Satisfaction and Attitudes Questionnaires, face-toface component

Positive Course Aspects 
Many respondents highlighted the positive aspects of sharing experiences with multidisciplinary colleagues from different organizations and regions across Bolivia (33 responses). Participants appreciated the "different points of view" of their colleagues representing different academic disciplines and social sectors. One respondent commented that the "diversity of the participants allowed us to know their experiences." Many respondents indicated that the participatory course pedagogy was the most positive aspect of their TOT experience (17 responses). The interactive group work and case studies, where "supportive and active participants shared experiences" were highlighted as positive examples. "Participant solidarity" and "collective participation" where groups engaged in active discussions were mentioned as key components of the positive teaching/ learning atmosphere. Learning new bioethics and research ethics content (16 responses) including "Clear competencies, terminology, and consulting with the teachers/specialists on bioethics concepts" were consistently mentioned as positive experiences. The "organization, methodology and teacher quality" were also appreciated by the respondents (15 responses).

\section{Negative Course Aspects}

Respondents reported negative course aspects related to problems following the scheduled time for presentations, discussions and group activities (19 responses). Participants stated that more time should have been allocated for discussions and that a moderator could have helped facilitate discussions. Only a few respondents reported problems with faculty where presentations were not clear and faculty read too much information from the slides.

\section{Satisfaction and Attitudes questionnaires, online component}

\section{Positive Course Aspects}

Respondents highlighted the organization (20 responses) of the course specifically referring to the coordination of the course and the quality of the content, faculty, and bibliography/resource materials. Respondents valued of the distance learning approach that enabled participants to study during convenient times. For example, "People who work during the day had the opportunity to participate in the important course activities related to human subject research." The diverse, dynamic and active participants were mentioned as positively contributing to the value of the virtual course.

\section{Negative Course Aspects}

Respondents cited several themes as challenges/ negative aspects of the online course component including some negative evaluations related to faculty communication (6 responses) with participants stating that the teachers did "not communicate well or provide much support to clearly explain the instructions and terminology". One respondent described the significant "challenges

Table 2. TOT Perceptions and Attitudes

\begin{tabular}{|l|l|}
\hline Face-to Face Component* & \\
\hline Positive Aspects ( $\mathrm{n}=81)$ & Negative Aspects $(\mathrm{n}=36)$ \\
\hline Participant Characteristics (33) & Time management (19) \\
\hline Pedagogy (17) & Faculty Communication (3) \\
\hline New knowledge/information (16) & Coordinators (2) \\
\hline Curriculum/teachers (15) & Venue (2) \\
\hline Online Component* & \\
\hline Positive Aspects ( $\mathrm{n}=33)$ & Negative Aspects $(\mathrm{n}=28)$ \\
\hline Course organization and coordination (20) & Faculty Communication (6) \\
\hline Pedagogy (9) & Online Pedagogy (6) \\
\hline Participant Characteristics (3) & Limited Time (6) \\
\hline New knowledge/information (1) & Technological problems (5) \\
\hline & Bibliography and resources (5) \\
\hline
\end{tabular}

${ }^{*}$ Numbers in parentheses indicate the number of responses for each theme. 
he/she had when reading the new (research ethics) terms and felt exasperated when trying to understand the material." There were critiques about some aspects of the online teaching methods especially the lack of interaction in the virtual forums and chat discussions. Many respondents felt that there was too much work in the virtual course and that there was not enough time to complete all the requirements. A few participants had some technical problems with the online platform stating they could not "technically manage" the virtual course modules. Some respondents felt that the bibliography and course documents were insufficient or not readily available.

Recommendations for the online course component were also highlighted. Several respondents recommended that more time be given for the online course. One respondent suggested including more activities where participants would review research project proposals utilizing ethical guidelines but realized more time would be needed for these types of practical experiences. Several respondents recommended solutions to the online course technical and platform issues such as developing a course manual for participants with clear instructions for accessing and using the online course and changing to a more user friendly learning platform, for example Moodle.

\section{Potential Impact of the Training}

After completing the face-to-face training, 92\% of respondents indicated they would make changes in their research activities at their institution or in their communities based on the new information from the course. Respondents planned to present $\mathrm{RE}$ workshops for community groups focused on how human rights relates to research and the informed consent process. One respondent planned to return to his university and encourage the administration and faculty to create a REC and another respondent planned to move forward to recruit community representatives to serve on his institution's REC.

After the online training, $100 \%$ of the respondents indicated they would make changes in their research activities at their institution or communities based on the new information they learned in the TOT course. They recommended teaching health science students the importance of RE and research design for their graduate thesis projects, creating RECs and inviting community members as participants, training university faculty, improving attitudes related to RE among community and academic leaders, and increasing multidisciplinary participation in all university health science teaching and research.

\section{Practicum - Dissemination}

During the 3 month practicum, TOT participants provided RE presentations and workshops to their university, civil society organizations and a range of community groups. Over 3,700 people including medical residents, community organizations and human rights groups, in four different states participated in these RE dissemination workshops. A manuscript summarizing these outreach activities is currently in development.

\section{Discussion}

The TOT was successfully implemented in Bolivia with high levels of participation by teams of university faculty, researchers and community health leaders from four different Bolivian states. Nineteen participants completed on face-to-face training and 16 completed the online training. Pre/Posttest results indicated significant increases in overall RE knowledge. Results from the participant Satisfaction and Attitude questionnaires emphasized high levels of overall satisfaction with the TOT course focused on new knowledge gained and participants' intention to change research practices in their universities or community organizations to incorporate RE principles. Participant recommendations will be important to improving future RE training efforts.

\section{Study Limitations}

The results of the TOT course may not be generalizable to future RE master's level courses which would require a significantly increased commitment of time and effort by the participants. The RE curriculum for a future course will also present more in depth RE information than was appropriate for the relatively brief TOT training reviewed for this paper. Although the types of individuals recruited for a more in depth master's 
level course may be similar to those recruited for the TOT, our results may not be generalizable to future more intensive RE training efforts in Bolivia.

\section{Challenges of TOT Model}

To use virtual modules and education platforms, technology skills are required which could limit the participation of some students and the ability to monitor student learning. The lack of face-toface contact and facilitator interaction can diminish the possibility of support and mentoring provided by instructor and limit in depth discussions or clarifications of the concepts.

\section{Lessons Learned}

An important aspect of the TOT course development was the essential role of the Steering Committee in developing and overseeing all aspects of the design and implementation of the course. The Steering Committee meetings were an opportunity not only to collaboratively accomplish significant work tasks necessary for successful implementation of the TOT but also to forge professional relationships that will be essential for developing future research and RE efforts in Bolivia.

TOT participants emphasized the importance of building teams, utilizing interactive learning strategies and providing flexibility through incorporating online learning. Results from the review of NIH/FIC funded RE programs also emphasized the importance of utilizing multiple pedagogical approaches to adapt to the learning needs of the trainees (14). Including leaders from religious organizations and human rights groups as members of the regional teams was cited as strengths of the TOT course. Community members added important new perspectives to course discussions and group activities. Community member participants were able to complete the face-to-face and online modules with similar participation rates and similar test scores assessing knowledge gained as the university faculty participants.

\section{Adult Learning Methods}

TOT participants highlighted the value of the interactive group learning activities which of- fered them opportunities to apply RE principles to "real world" research issues. Lolas and Rodriquez(19) found in their extensive experience developing and implementing Bioethics and RE training programs at the Interdisciplinary Center for Bioethics of the University of Chile (CIEB) that guiding principles for training focused on the importance of group and social interaction in the learning process including methodological pluralism (multidisciplinary approach to problem solving), culture of dialogue (sharing of perspectives), open-mindedness, attitudinal change, improved communication skills, tolerance and ability to listen(19). These principles are consistent with the comments highlighted by TOT participants as positive aspects of the face-to-face training that incorporated significant participation of trainees through group work.

\section{Research Ethics Dissemination}

Participants demonstrated significant commitment to extending RE related knowledge and practices learned in the TOT program to their regional communities as evidenced from the significant dissemination efforts conducted in the TOT practicum period. University faculty used materials from the bibliography provided by the TOT course to develop lectures for undergraduate and graduate health science students. Community members conducted workshops to raise awareness of the importance of RE principles for research within their organizations and civil society groups. The TOT curriculum development and course implementation ignited an enthusiastic response among participants representing faculty, researchers and civil society leaders to inspire and educate a range of health science professionals and community members about the importance of bioethics and research ethics in Bolivia.

\section{Research Ethics Collaboration}

From the results of the Pre/Posttests, Completion of Online Modules, and Satisfaction and Attitudes questionnaires, it was clear that course content related to international RE standards was new to many of the course participants. For this reason, principles and perspectives from PAHO, CITI, CIEB, TUC and the Bolivian scientists were helpful to understand international RE is- 
sues. Broadening RE education partnerships to include international RE expert groups, public health sector, community-based organizations and PAHO will also strengthen the capacity of future efforts to implement a master's level RE educational program in Bolivia. A mixture of national and international faculty and educational resources will be important for developing innovative and effective approaches to improving RE knowledge and practices throughout Bolivia.

\section{Next steps}

It is essential to develop and implement a master's level RE course to significantly improve the RE capacity in Bolivia. Teams of experts are needed in each department/region to provide educational support for health scientists and researchers in the public and private sector. These individuals can provide mentorship for researchers and REC members. Changing research related practices in universities, hospitals and health clinics will require a concerted effort that will be best sustained not through trained individuals working in isolation in universities but through teams of individuals who are trained and motivated to strengthen RE practices and policies in their institutions and communities. Lolas and Rodriquez (2012) present an in depth discussion of the rationale for the importance of RE training in Latin America. They recommend a combination of face-to-face and online learning "within the same cultural community" in consideration for the local/regional nature of ethical considerations related to research(19). They also emphasize the importance of addressing the widening disparity in research resources including financial and educational support for research and RE by providing high quality, culturally appropriate RE training programs within the context of particular countries and regions(19). A central aim of the Bolivian RE TOT program was to support teams of Bolivian academics, researchers and community leaders who could work collaboratively to develop specific RE programs in Bolivia.

This study suggests that a face-to-face and online hybrid course structure utilizing multidisciplinary participatory pedagogies may be an optimal approach to collaborative learning, changing attitudes/perceptions, increasing knowledge, and improving skills related to human subject research in Bolivia. Additional training and mentoring for RE faculty related to virtual teaching methodologies will be required as well as clearer platform guides/ instructions and improved distance learning support technology. The lessons learned and educational implications from the TOT will be important for creating an effective and successful master's level RE education course in Bolivia.

\section{Acknowledgements}

We graciously acknowledge the Steering Committee members who designed and implemented the TOT course. We also recognize the invaluable contribution of the TOT faculty, participants, administrative personnel and university authorities who actively engaged in these efforts to develop research ethics education, knowledge and skills among Bolivian academics, researchers, health professionals and community leaders. Research reported in this publication was supported by the Fogarty International Center of the $\mathrm{Na}$ tional Institutes of Health under Award Number R25TW009509. The content is solely the responsibility of the authors and does not necessarily represent the official views of the National Institutes of Health. 


\section{References}

1. United Nations Educational, Scientific and Cultural Organization (UNESCO). The Crucial Role of Science for Sustainable Development and the Post' 2015 Development Agenda, 2014.

2. Universidad Mayor de San Simon (UMSS), Vicerrectorado. Dirección de Investigación Científica y Tecnología. For Research Cooperation between UMSS and SIDA 2013-2017. Concept note; 2011.

3. Sullivan S, Aalborg A, Basagoitia A, Cortes J, Lanza O, Schwind J. Exploring Perceptions and Experiences with Research Ethics in Bolivia. Journal of Empirical Research Human Research Ethics 2015; 10(2): 185-195.

4. Swedish International Development Cooperation Agency, Sida. Tailor-made research can lift Bolivia out of poverty; 2014. Available from: http:/www.sida.se/English/where-we-work/Latin-America/Bolivia/examples-of-results/tailor-maderesearch-can-lift-bolivia-out-of-poverty/

5. Zwareva Mashiri E. Los Comités de Ética de Investigación Biomédica y Psicosocial en Bolivia. Acta Bioethica 2010; (16) 1: 87-91.

6. Aalborg A, Sullivan S. Consortium of Universities for Global Health (CUGH). Annual Conference PO02.235 Application of Research Ethics in Bolivia: Perspectives of Bolivian Health Scientists and Health Sector Leaders, 2014.

7. Department of Health and Human Services, National Institutes of Health. International Research Ethics Education and Curriculum Development Award (R25). Funding Opportunity Announcement (FOA) Number PAR-13-027.

8. Kalichman MW, Plemmons DK. Research Agenda: The Effects of Responsible-Conduct-of-Research Training on Attitudes. Journal of Empirical Research on Human Research Ethics 2015; 10(5): 457-459.

9. Bloom BS, Englehart MB, Furst EJ, Hill WH, Krathwohl DR. Taxonomy of Educational Objectives, the classification of educational goals, Handbook I: Cognitive Domain. New York: McKay; 1956.

10. Jhpiego Coorporation. Training Skills for Health Care Providers. Johns Hopkins University; 2010

11. Diaz DP, Cartnal RB. Students' learning styles in two classes: Online distance learning and equivalent on campus. College Teaching 1999; 47(4):130-135.

12. Peacock M. Match or mismatch? Learning styles and teaching styles in EFL. International Journal of Applied Linguistics 2001; 11(1): 1-20.

13. Vaughn L, Baker R. Teaching in the medical setting: Balancing teaching styles, learning styles and teaching methods. Medical Teacher 2001; 23(6): 610-612.

14. Matar A, Garner S, Millum J, Sina B, Silverman H. Curricular Aspects of the Fogarty Bioethics International Training Programs. Journal of Empirical Research on Human Research Ethics 2014; 9(2): 12-23.

15. Taylor D, Hamdy H. Adult learning theories: Implications for learning and teaching in medical education: AMEE Guide No. 83. Medical Teacher 2013; 35(11): e1561-e1572. DOI: 10.3109/0142159X.2013.828153

16. Lotrecchiano GR, McDonald PL, Long T, Zajicek-Farber M. Blended Learning: Strengths, Challenges, and Lessons Learned in an Interprofessional Training Program. Maternal Child Health Journal 2013; 17(9): 1725-1734.

17. Family Health International (FHI 360). Research Ethics Training Curriculum, 2nd Edition, 2011. Available from https:// www.fhi360.org/sites/all/libraries/webpages/fhi-retc2/

18. Glaser BG, Straus AL. The discovery of grounded theory: Strategies for Qualitative Research. New Brunswick, NJ: Transaction Books; 2009.

19. Lolas F, Rodriquez E. Ethics in psychosocial and biomedical research. A training experience at the Interdisciplinary Center for Bioethics (CIEB) of the University of Chile. Acta Bioethica 2012; 18(1): 9-56.

Received: April 28, 2016

Accepted: July 22, 2016 